\title{
Research on Deformation Law of Surrounding Rock During Excavation of Tunnel
}

\author{
Deshen Zhao ${ }^{1, a}$ Yunping Wang ${ }^{1, b}$ \\ ${ }^{1}$ Key Laboratory of Liaoning Province for Prediction and Control on Complicated Structure \\ System,Dalian University, Dalian 116622, China \\ a zhaodeshen@dlu.edu.cn , bWangYunPingJG211@163.com
}

Keywords: surrounding rock deformation; finite element software FLAC3D; deformation and failure of surrounding rock

Abstract. Research on the deformation and failure of surrounding rock is very important to the excavation of tunnel, in this paper, based on the geological data and mining conditions of a tunnel engineering using the finite element software FLAC3D to simulate the process of tunnel excavation, and the failure characteristics of surrounding rock under the action of mining is analyzed. In order to better analyze the rule of vertical displacement after tunnel excavation, some nodes of the vault and bottom of the tunnel are selected to monitor the vertical displacement, and the results of numerical simulation are close to the measured values. Providing effective theoretical support for the safety construction of tunnel engineering.

\section{Introduction}

The deformation and failure of surrounding rock is very important to the excavation of tunnel ${ }^{[1,2]}$, the research on deformation mechanism and failure law of rock mass structure ${ }^{[3,4]}$, provide scientific and technical support for tunnel safety excavation and maintenance, enhancing the ability of predicting and preventing the tunnel geological disasters, for the safety of engineering construction and saving the investment guarantee.

\section{Engineering profile}

The full length of the metro line is $2.9 \mathrm{~km}$, the interval of shield is $2.3 \mathrm{~km}$, and the distance of two tunnels is about $10 \mathrm{~m}$, the depth of it is about $15 \mathrm{~m}$. The diameter of shield segment lining is $5400 \mathrm{~mm}$, the lining thickness is $300 \mathrm{~mm}$ (the outer diameter is $6000 \mathrm{~mm}$ ). The width of segment is $1200 \mathrm{~mm}$. Each ring of lining segment consists of 3 pieces of standard, 1 pieces of cap and two Pro tabs, the lining segment is regarded as homogeneous concrete tubular ring, the strength reduction coefficient is 0.9 at the position of interface. Using C50 concrete, the anti permeability level is S12. Shield tail grouting when the lining segment is installed, the fracture surface of the shield tail as shown in figure 1.

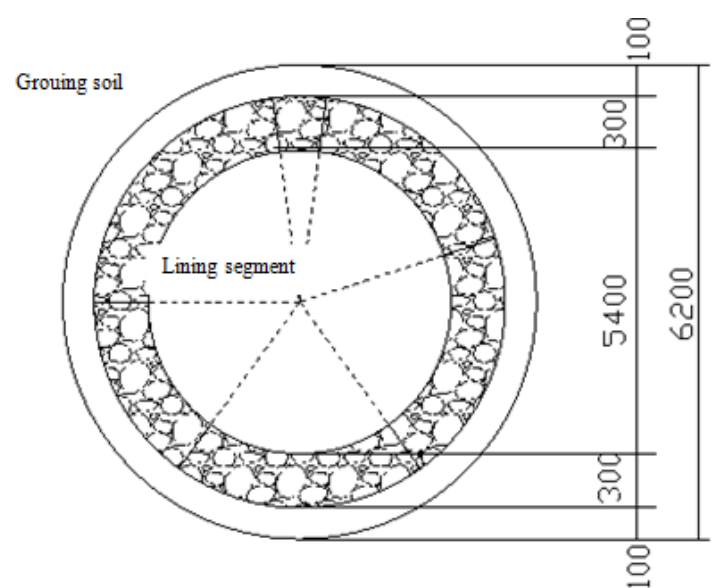

Fig. 1 Cross section of shield tail 


\section{Geological conditions and mechanical parameters}

According to the field geological survey report, the distribution of strata and related parameters can be obtained. Specific calculation parameters are shown in table1.

Tab. 1 Physical and mechanical parameters of soil

\begin{tabular}{cccccccc}
\hline type & $\begin{array}{c}\text { thickness/ } \\
\mathrm{m}\end{array}$ & $\begin{array}{c}\text { unit weight } \\
/ \mathrm{kN} \cdot \mathrm{m}^{-3}\end{array}$ & $\begin{array}{c}\text { modulus of } \\
\text { elasticity } \\
/ \mathrm{Mpa}\end{array}$ & $\begin{array}{c}\text { poisson } \\
\text { ratio }\end{array}$ & $\begin{array}{c}\text { cohesive } \\
\text { force } \\
/ \text { Kpa }\end{array}$ & $\begin{array}{c}\text { friction } \\
\text { angle } \\
\rho\end{array}$ & $\begin{array}{c}\text { osmotic } \\
\text { coefficient } \\
/ \mathrm{cm}^{-1}\end{array}$ \\
\hline $\begin{array}{c}\text { plain fill } \\
\text { clay }\end{array}$ & 4.4 & 16.5 & 20 & 0.38 & 11 & 12.9 & $1.6 * 10^{-8}$ \\
$\begin{array}{c}\text { pebble } \\
\text { weathered } \\
\text { rock } \\
\text { middle }\end{array}$ & 2.4 & 18 & 23 & 0.30 & 20.8 & 25.3 & $3.23 * 10^{-8}$ \\
$\begin{array}{c}\text { weathered } \\
\text { rock }\end{array}$ & 1.0 & 19.5 & 25 & 0.30 & 43 & 24.6 & $2.21 * 10^{-9}$ \\
$\begin{array}{c}\text { grouting } \\
\text { soil }\end{array}$ & 24.1 & 25.3 & 46 & 0.30 & 60 & 37.8 & $3.78 * 10^{-10}$ \\
\hline
\end{tabular}

\section{Model building}

The size of the calculate model is $50 \mathrm{~m} \times 36 \mathrm{~m} \times 48 \mathrm{~m}(\mathrm{X} \times \mathrm{Y} \times \mathrm{Z}), \mathrm{X}$ is horizontal, $\mathrm{Y}$ is the direction of tunnel excavation, $Z$ is vertical, the section layout of metro shield tunnel as shown in figure2. The calculation model was divided into 41112 units, 45521 nodes. In order to simplify the calculation, each longitudinal excavation simulation calculation with 5 segment as a group(each ring width is $1.2 \mathrm{~m}$ ), each time the tunnel length of longitudinal construction is $6.0 \mathrm{~m}$. 3D model of double line shield tunnel as shown in figure3. The top surface is a free boundary, but the boundary of left and right sides and the bottom are impermeable boundary.

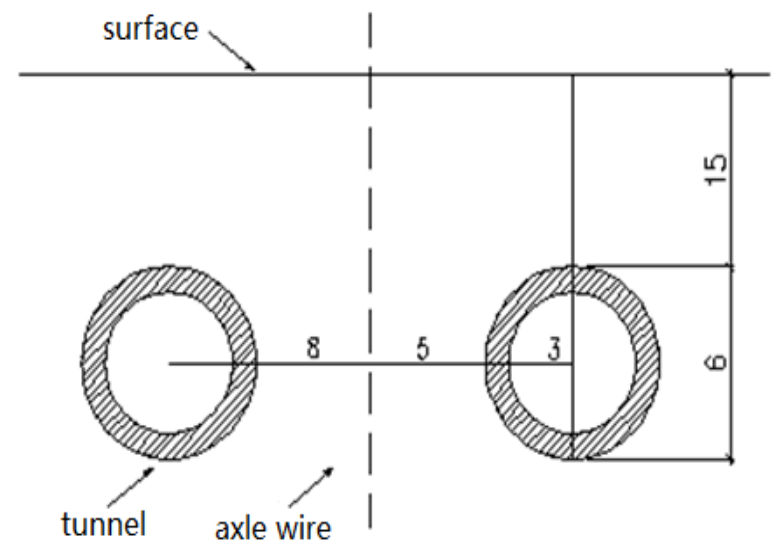

Fig.2 The $Y=0 \mathrm{~m}$ section layout of metro shield tunnel

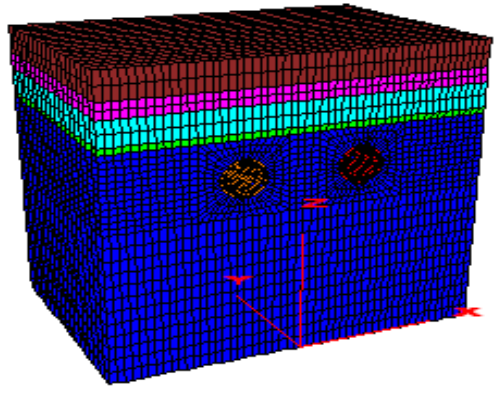

Fig.3 Dimensional model after the left and right tunnel excavation 


\section{Distribution law of displacement field of surrounding rock}

\subsection{Distribution law of horizontal displacement field of surrounding rock}

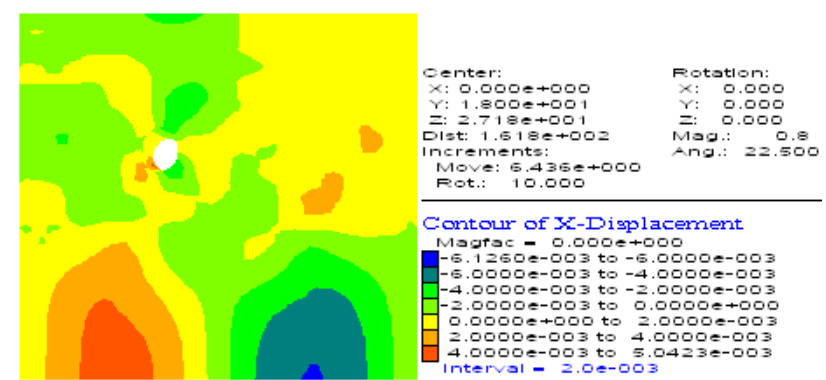

Fig.4 Surrounding rock horizontal displacement nephogram after the left tunnel excavation

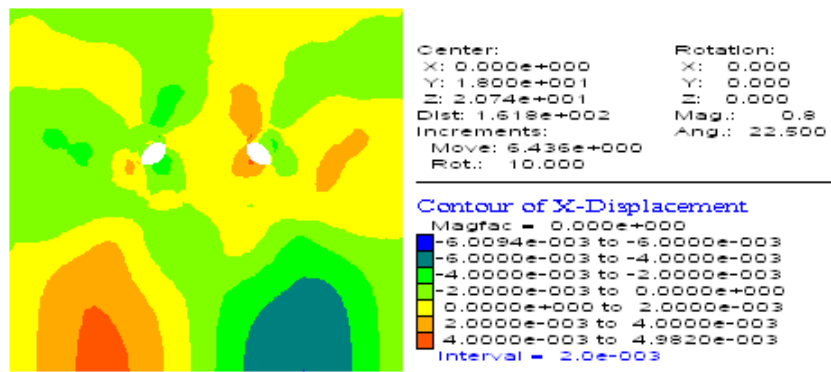

Fig.5 Surrounding rock horizontal displacement nephogram after the left and right tunnel excavation

Figure 4 is the cloud picture of horizontal direction of the surrounding rock after excavation of the left tunnel, figure 5 is the cloud picture of horizontal direction of the surrounding rock after excavation of the right and left tunnel. Which provides for horizontal displacement to the right is positive, to the left is the negative, the unit is the meter. Can be known by figure4, the maximum positive displacement is concentrated near the excavation area, the maximum value of displacement is $5.04 \mathrm{~mm}$ which extended from the side wall of the tunnel to the two sides, the value of maximum negative displacement is $6.13 \mathrm{~mm}$. Can be known by figure5, the value of maximum positive displacement is $4.98 \mathrm{~mm}$ after excavation of the right and left tunnel, the displacement of surrounding rock of side wall is convergence to the hole, the value of maximum negative displacement is $6.01 \mathrm{~mm}$. From above, you can see that after the completion of the excavation of the left tunnel and the right and left tunnel, the horizontal displacement of the tunnel is relatively small, mainly because of the radial convergence of the tunnel, so that seepage field has little effect on the horizontal displacement of surrounding rock.

\subsection{Distribution law of horizontal displacement field of surrounding rock}

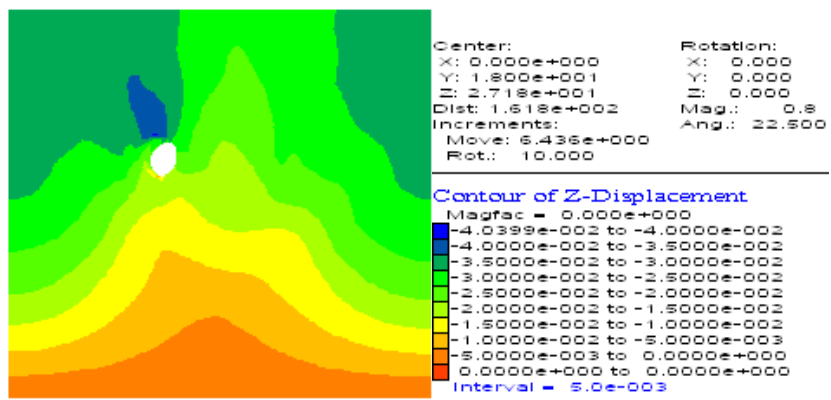

Fig.6 Surrounding rock vertical displacement nephogram after the left tunnel excavation 


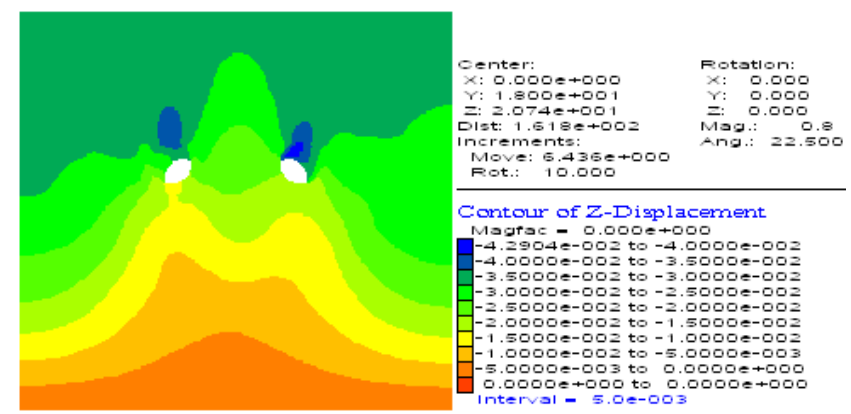

Fig.7 Surrounding rock vertical displacement nephogram after the left and right tunnel excavation

In order to better analysis of the law of vertical displacement of tunnel after excavation, some nodes are selected to monitor the vertical displacement of the vault and arch bottom of the tunnel, the location of monitor nodes and numbers as shown in table2.

Tab. 1 Monitoring node location of surrounding rock displacement

\begin{tabular}{ccc}
\hline Serial number & coordinate position $/ \mathrm{m}$ & identifier \\
\hline 1 & $-8,18,3$ & 15 \\
2 & $-8,18,-3$ & 21 \\
3 & $8,18,3$ & 24 \\
4 & $8,18,-3$ & 26 \\
\hline
\end{tabular}

Tunnel arch and arch bottom monitoring node settlement graph after the left tunnel and the left and right excavation as shown in the following figures.

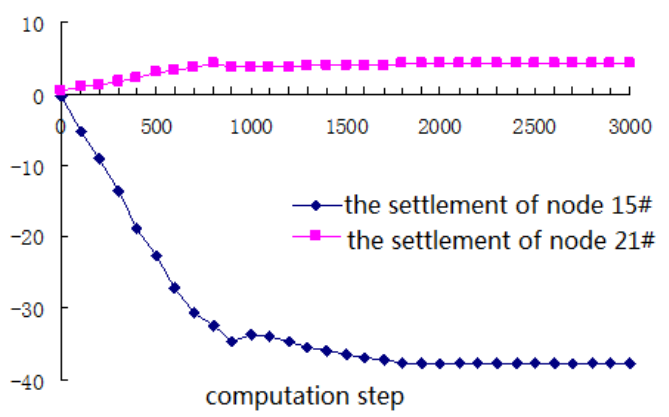

Fig.8 Tunnel arch monitoring node settlement graph after the left tunnel excavation

The numerical simulation program provides that upward displacement is positive, the opposite side is negative, the unit is meter. From the figure6 and figure8 we can know that, the settlement of surrounding rock of tunnel vault more close to the excavation area more bigger; the vertical displacement of the surrounding rock of the tunnel excavation reaches the surface, the deformation of surrounding rock is obvious in the range of tunnel excavation, the vertical displacement of the surrounding rock of the vault is negative, which indicates that settlement occurred for vault after tunnel excavation, and the value of maximum settlement displacement is $37.9 \mathrm{~mm}$; the vertical displacement of the bottom surrounding rock of the tunnel is positive, which indicates that the bottom of the arch is raised, which mainly because of the excavation and unloading caused by the bottom of tunnel rebound, and its displacement is almost zero.

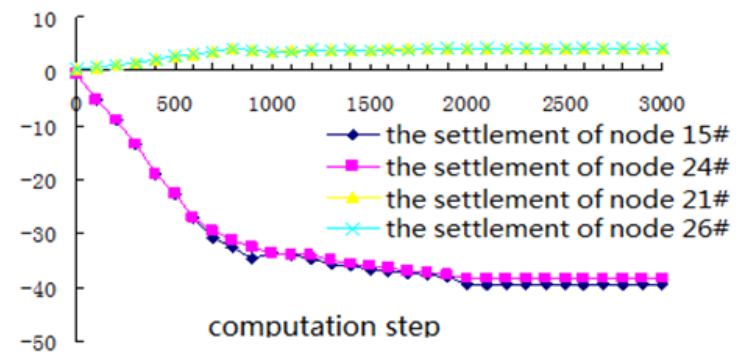

Fig.9 Tunnel arch monitoring node settlement graph after the left and right tunnel excavation 
Figure7 is the surrounding rock vertical displacement nephogram after the left and right tunnel excavation. From the figure7 and figure9 we can know that, ground settlement happened above the tunnel, and the value of maximum settlement displacement of the vault is $39.6 \mathrm{~mm}$, after tunnel excavation the vertical displacement of the bottom surrounding rock of the tunnel is zero. The vertical displacement of the vault and the bottom of the arch are increased after the left and right tunnel excavation. And the vertical displacement of surrounding rock of the left side of the tunnel is slightly larger than that of the right side of the tunnel, which is mainly due to the left tunnel was excavated first and there is a certain degree of disturbance .

\section{Conclusion}

1.After the completion of the excavation of the left tunnel and the right and left tunnel, the horizontal displacement of the tunnel is relatively small, which is mainly because of the radial convergence of the tunnel, so that seepage field has little effect on the horizontal displacement of surrounding rock. 2.The settlement of surrounding rock of tunnel vault more close to the excavation area more bigger; the vertical displacement of the vault and the bottom of the arch are increased after the left and right tunnel excavation. And the vertical displacement of surrounding rock of the left side of the tunnel is slightly larger than that of the right side of the tunnel, which is mainly due to the left tunnel was excavated first and there is a certain degree of disturbance .

\section{Acknowledgements}

The author would like to thank the financial support by the National Natural Science Foundation of China (Grant No. 51274051).ZHAO Deshen(1957 - ) male,the elm city of Jilin Province,university professor, Doctor. E-mail: zhaodeshen@dlu.edu.cn.

\section{References}

[1] Guo Fu-li. Research on large deformation mechanism of soft rock of baozhen tunnel [D]. Beijing Jiaotong University, 2010.

[2] Feng Jing-wei. Study on stability of the surrounding rock and supporting the deep-buried tunnel [D]. Xi'an University of Science And Technology, 2009.

[3] Wang Guo-yan. Study on crack propagation laws and failure mechanism of rock mass induced by mining [D]. Liaoning Technical University, 2010.

[4] Allen, Zhang Ding-li, Li Bing and so on. Coupled fluid-solid analysis of the surrounding rock stability of the subsea tunnel during construction process [J]. China Railway Science, 2010,31 (3): 35-41. 